\title{
COM \\ Celebrating the complexity and diversity that is science communication around the globe
}

Reviewed Book

Reviewed by

Abstract

Keywords

DOI
Gascoigne, T., Schiele, B., Leach, J., Reidlinger, M., LeWenstein, B. V., MAssarani, L. AND Broks, P. eds. (2020). Communicating Science, A Global Perspective. ACTON, ACT, AUSTRALIA: ANU PRESS

\section{Emma Weitkamp}

This book review considers the contribution of Communicating Science, A Global Perspective to our understanding of the history of science communication across the globe. With 40 chapters and nearly 1000 pages of text, this substantial book provides insights into the unique histories of science communication in 39 countries across all regions of world.

History of public communication of science; Science communication in the developing world

https://doi.org/10.22323/2.19060701

Submitted: 12th October 2020

Accepted: 13th October 2020

Published: 16th November 2020

If you've ever wondered how diverse a field science communication is then Communicating Science, A Global Perspective will quench your thirst. This incredible tome provides a comprehensive look at the history of science communication across 39 countries. This is truly a diverse collection of chapters with five countries represented from Africa, seven from the Americas, 11 from Asia and 16 from Europe and Australasia; this has to be one of the first attempts at a global history of science communication. Represented within the 40 chapters, and nearly 1000 pages of text, are perspectives from the global South and the global North. These histories are necessarily diverse as are the definitions of and terms used for science communication to be found inside the books covers.

Nevertheless, there are some trends that can be identified and which are helpfully pulled out in the introductory chapters by Toss Gascoigne and Bernard Schiele. For example, it seems that many countries begin their narrative of modern science communication in the optimism of the post-World War II era, where science was seen as one of the key ways in which to increase wealth and tackle both the health and environmental challenges faced by society. However, this early view of science communication is challenged, particularly in more modern conceptualisations of 
the field. For example, Manzoor Soomoro and Khalil Raza, in their chapter on Pakistan, critique the extent to which science and science communication have met this early promise and contributed to socio-economic development. These early antecedents of modern science communication explain, perhaps, the rise in the public understanding of science model of science communication, a model which sees science communication as seeking to 'increasing public acceptance, awareness and education' [Gascoigne and Schiele, 2020, p. 9] with respect to science and which can be seen in some approaches to science communication today.

That science communication faces many challenges is clearly evident throughout the chapters of this book. Challenges are wide-ranging whether that is to sustain interest in science communication programmes perhaps as governments change, finding funds for infrastructure and the associated limits that lack of funding can have on achievements in science communication. Other challenges have emerged more recently and include challenges associated with valuing indigenous knowledge alongside Western science, and the lack of reward structures for scientists which may discourage them from undertaking public engagement work.

Editors Bernard Schiele and Toss Gascoigne had gone some way to synthesise the goldmine of information represented in the chapters held within this book. They argue that science communication, at least as presented in this book, represents three distinct areas: a field of practice, a media subfield and an academic field. Looking at the data collected, the field of practice has emerged over many years and in quite different ways across countries. For example, Norway reports the first science centre opening in 1914, though most science centres were opened in the mid-1970s. Similarly associations of science journalists become much more common from the mid-1970s, though the first appears in 1929 in Germany. Other markers of science communication practice include the emergence of science weeks and science festivals. The media subfield is measured through the appearance of media dedicated to science such as dedicated radio and television programming, and popular science magazines.

In relation to science communication as an academic field, University courses offering training in science communication is one way the authors have sought to measure the increasing professionalisation of science communication. There were a few programmes emerging in the 1960s, though the majority of programmes begin in mid-1970s. It is worth noting that these may not be programmes fully dedicated to science communication, but instead may comprise modules or courses within broader programmes of study such as science journalism. Most of the countries represented in this book now have some training available in science communication, reflecting its global spread as a field of study. Masters degrees in science communication emerge from the 1980s onwards, and the first $\mathrm{PhD}$ programmes in science communication appear in the 1970s, though the majority of these also begin in the mid-80s. Researchers exploring science communication also have a choice of conferences to attend with many countries having national conferences dedicated to science communication research or practice. Overall the synthesis that Bernard Schiele and Toss Gascoigne have conducted, presents a picture of an increasing interest in science communication practice and research, an increase, they suggest, that is accelerating.

It would be impossible to do justice to all 40 chapters in the short book review, and for the patient reader detailed exploration whether of countries of interest or the broader picture this book paints is well worthwhile. This A-Z starts with Africa and 
ends with the U.S.A., visiting such diverse countries and associated perspectives as Argentina, Estonia, Ghana, Jamaica, Japan, Nigeria, the Philippines, Russia, South Korea, Thailand, Turkey and Uganda to name but a few. Each chapter has a local flavour, determined by the country context and authors' interests. Many, like the authors of the chapter on the U.S.A. (Bevan and Smith), faced significant challenges in trying to convey the complicated national landscape of science communication, and the range of historical factors that influenced its development nationally. Many may agree with Bronwyn Bevan and Brook Smith that 'it's complicated'.

A deeper look at this text will reward readers. For example, Margaret Kaseje and Verha Okeyo, in their chapter on health communication in selected African countries, highlight an interesting difference between the global South and the global North; in African countries, they argue, the history of colonisation means that people may not question science and health in the way that science is questioned in Northern regions. I'm sure other differences in context and history will emerge for the dedicated reader. The book, therefore, complements previous work published in JCOM exploring the contexts and history of science communication, for example the special issue on the history of science communication published in 2017 and co-edited by Luisa Massarani, Ildeu Moreira and Bruce Lowenstein. Several authors are represented in both this book and that special issue.

Communicating Science, a Global Perspective is available to download free from the Australian National University press, https: / / press.anu.edu.au/publications / communicating-science. You can download either the full book or individual chapters. Print copies are also available to purchase, though at Aus $\$ 150$ it is likely to be out of most people's reach.

References

Gascoigne, T. and Schiele, B. (2020). 'Introduction. A global trend, an emerging field, a multiplicity of understandings: science communication in 39 countries'. In: Communicating Science, A Global Perspective. Ed. by T. Gascoigne, B. Schiele, J. Leach, M. Riedlinger, B. V. Lewenstein, L. Massarani and P. Broks. Acton, ACT, Australia: ANU press. Chap. 1, pp. 1-14. https://doi.org/10.22459/CS.2020.

Author

Emma Weitkamp is Editor in Chief of JCOM and Associate Professor of Science Communication at the University of the West of England, Bristol, U.K. Emma teaches science communication at postgraduate and undergraduate level, as well as undertaking research on science communication, particularly considering the range of actors that contribute to the science communication landscape.

E-mail: emma.weitkamp@uwe.ac.uk.

\section{How to cite}

Weitkamp, E. (2020). 'Celebrating the complexity and diversity that is science communication around the globe'. JCOM 19(06), R01. https://doi.org/10.22323/2.19060701. 